\title{
Survival after extracorporeal membrane oxygenation in severe COVID-19 ARDS: results from an international multicenter registry
}

\author{
Alexander Supady ${ }^{1,2,3^{*}} \mathbb{C}$, Fabio Silvio Taccone ${ }^{4}$, Philipp M. Lepper ${ }^{5}$, Stephan Ziegeler ${ }^{6}$ and \\ Dawid L. Staudacher ${ }^{1,2}$ for the COVEC-Study Group
}

Survival of coronavirus disease 2019 (COVID-19) patients with severe respiratory failure treated with venovenous extracorporeal membrane oxygenation $(\mathrm{V}-\mathrm{V}$ ECMO) ranges around $60 \%$, according to recent studies $[1,2]$. Initial recommendations for the use of $\mathrm{V}-\mathrm{V}$ ECMO in COVID-19-related acute respiratory distress syndrome (ARDS) were largely based on studies from the pre-COVID-19 era [3, 4]. V-V ECMO was initiated in younger patients (i.e., $<71$ years) and in those with rather short duration of mechanical ventilation (MV) prior to ECMO (i.e., $<7$ or $<11$ days, respectively) $[1,5]$. While it is reasonable to focus on selected ECMO cohorts in controlled trials, survival of COVID-19 patients treated with ECMO beyond these limitations remains unclear, so far. Here, we report survival data of COVID-19 ARDS patients treated with V-V ECMO from a large, international multicenter registry.

Data were collected retrospectively from medical records at 3 ECMO centers in the USA, 9 in Germany, and 1 in Switzerland, Belgium, and Italy. At the participating centers, all patients with reverse transcriptase polymerase chain reaction ( $\mathrm{rtPCR}$ ) positive testing for SARS-CoV-2, who received V-V ECMO from March 12 to June 5, 2020 (i.e., during the first wave of the pandemic), were included.

\footnotetext{
*Correspondence: alexander.supady@universitaets-herzzentrum.de ${ }^{1}$ Department of Medicine III (Interdisciplinary Medical Intensive Care), Medical Center, Faculty of Medicine, University of Freiburg, Hugstetter Strasse 55, 79106 Freiburg, Germany

Full list of author information is available at the end of the article
}

A total of 127 patients were analyzed: 53/127 (41.7\%) of them survived at day 90 after ECMO implantation (Table 1). Higher survival was observed in patients younger than 71 years when compared to others (Fig. 1: $110 / 127,45.5 \%$ vs. $17 / 127,17.6 \%, p=0.004)$. However, patients being on MV before ECMO for less than 7 days had slightly higher survival rate than those with longer MV course though not reaching statistical significance (77/127, 46.8\% vs. 50/127, 34.0\%; $p=0.167)$. Similar results were observed when the duration of MV was dichotomized in $<11$ and $\geq 11$ days $(101 / 127,45.5 \%$ vs. 26/127, 26.9\%; $p=0.044$ ).

Our findings derive from an international multicenter registry of COVID-19-related ARDS patients treated with V-V ECMO. 90-day survival in our cohort was $41.7 \%$, which was lower than previously described for COVID-19 patients treated with V-V ECMO in large registries and survival reported for non-COVID-19 ARDS patients $[1,2,5]$. The lower survival rate might be attributable to a more liberal use of V-V ECMO in this realworld cohort outside a prospective trial or to a different policy than in other ECMO centers. Even though survival of patients treated with ECMO even after longer periods of time of MV was lower than survival of patients with early initiation of ECMO, the latter still showed considerable survival rates. Our results therefore challenge strict contraindications for initiation of ECMO in COVID19 patients solely based on duration of MV. Moreover, even though 90-day-survival of patients aged $\geq 71$ years was significantly lower than for patients $<71$ years, not all treatments in this elderly population ended fatal. original author(s) and the source, provide a link to the Creative Commons licence, and indicate if changes were made. The images or other third party material in this article are included in the article's Creative Commons licence, unless indicated otherwise in a credit line to the material. If material is not included in the article's Creative Commons licence and your intended use is not permitted by statutory regulation or exceeds the permitted use, you will need to obtain permission directly from the copyright holder. To view a copy of this licence, visit http://creativecommons.org/licenses/by/4.0/. The Creative Commons Public Domain Dedication waiver (http://creativeco mmons.org/publicdomain/zero/1.0/) applies to the data made available in this article, unless otherwise stated in a credit line to the data. 


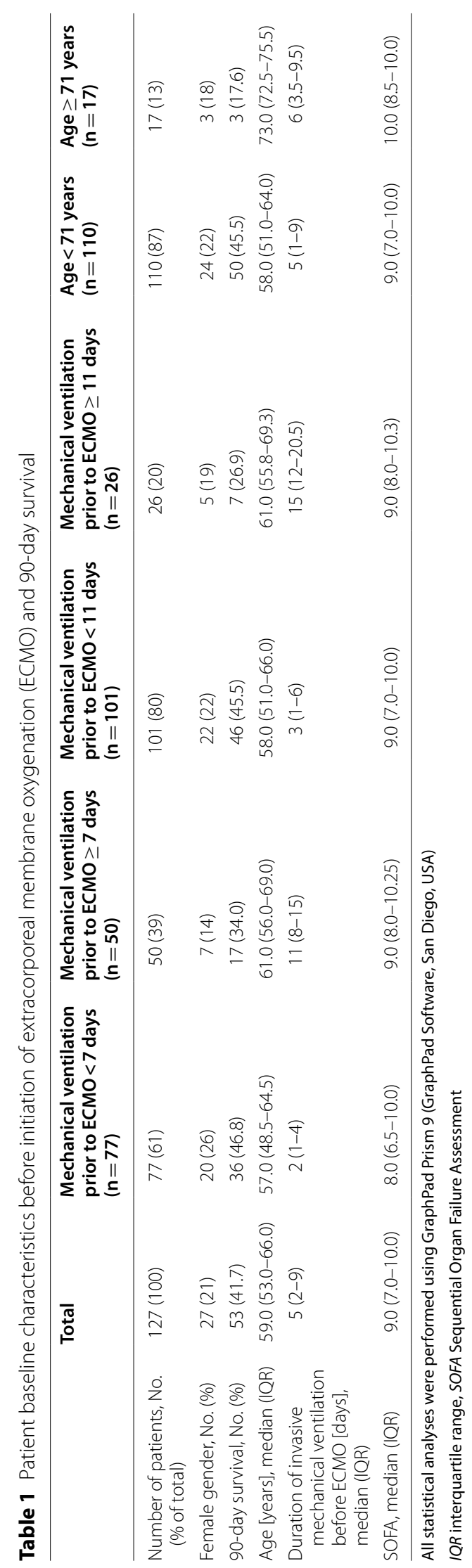




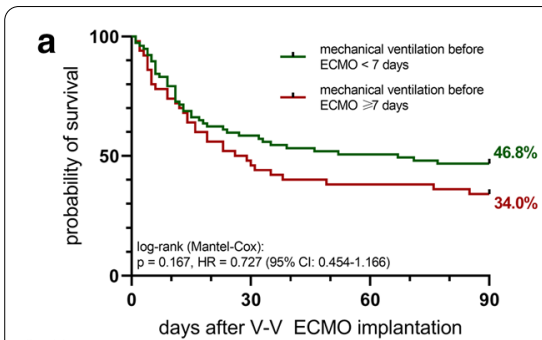

$\begin{array}{llll}\# \text { at risk } \\ \text { ventilation }<7 \mathrm{~d} & 77 & 46 & 40\end{array}$ days after V-V ECMO implantation

b

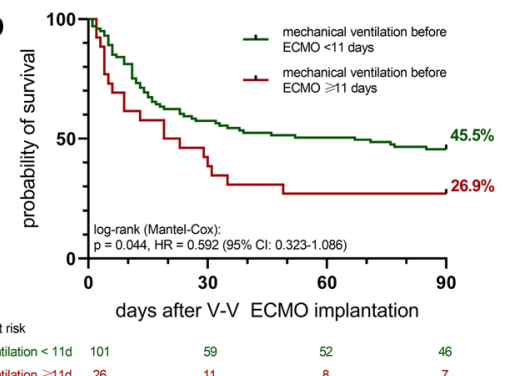

C

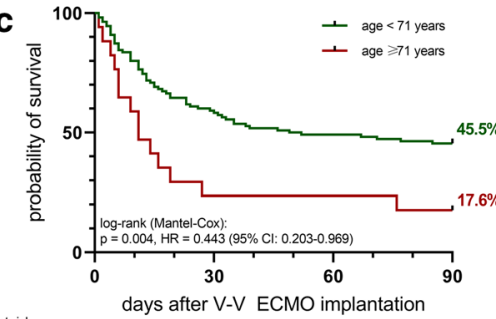

\# at risk $\begin{array}{lcccc}\text { age }<71 \text { years } & 110 & 65 & 55 & 50 \\ \text { age } \geqslant 71 \text { years } & 17 & 5 & 5 & 3\end{array}$

Fig. 1 Kaplan-Meier curves for a survival of patients on mechanical ventilation $<7$ days or $\geq 7$ days before V-V ECMO (Cox proportional hazards model including SOFA score: $p=0.215$, HR 0.755 (95\% Cl 0.484-1.178), b survival of patients on mechanical ventilation $<11$ days or $\geq 11$ days before V-V ECMO (Cox proportional hazards model including SOFA score: $p=0.052$, HR 0.604 (95\% Cl 0.363-1.005), c survival of patients aged $<71$ years or $\geq 71$ years before V-V ECMO (Cox proportional hazards model including SOFA score: $p=0.008, \mathrm{HR} 0.464$ (95\% Cl 0.263-0.820). All statistical analyses were performed using GraphPad Prism 9 (GraphPad Software, San Diego, USA) and SPSS 27 (IBM, Armonk, New York, USA). V-V ECMO veno-venous extracorporeal membrane oxygenation

Therefore, age limits should be viewed with caution and decisions for or against the use of ECMO for patients above 70 years of age should be performed on an individual case-by-case level.

The main strength of our study is the high number of patients and multicenter analysis. However, our results are limited due to the retrospective design, small case volume at each center, the lack of a control group, and potential differences in ECMO practices and criteria for ECMO at the different centers.

In conclusion, our data may support the use of $\mathrm{V}-\mathrm{V}$ ECMO in severe COVID-19 ARDS, also after prolonged periods of mechanical ventilation in selected patients. Upper age limits should be viewed with caution and not taken as the sole reason to withhold ECMO treatment.

\section{Acknowledgements}

The authors thank Franziska Frech, Moritz Kuhl, Sissi Mueller, Timm Zahn, and Arina-Cornelia Chifulescu for their support in the collection and evaluation of patient data.

Collaborating authors (COVEC-study group): Jeff DellaVolpe, Methodist Hospital, San Antonio, Texas, USA; Dominik Scharpf, SLK-Hospital Heilbronn, Germany; Matthias UImer, RKH Hospital Ludwigsburg, Germany; Maximilian Halbe, Heart Center, University Hospital Zurich, Switzerland; Alexander Vogt, Department of Medicine III, University Clinic Halle (Saale), Germany; Raj Ramanan, University of Pittsburgh Medical Center (UPMC), Pennsylvania, USA; David Boldt, UCLA Healthcare System, Los Angeles, USA; Stephanie-Susanne Stecher, Medical Department II, LMU Hospital Munich, Germany; Andrea Montisci, Istituto Clinico Sant'Ambrogio, University of Milan, Italy; Tobias Spangenberg, Department of Cardiology, Angiology and Intensive Care, Marien Hospital Hamburg, Germany; Olivier Marggraf, Asklepios Clinic North, Hamburg, Germany; Chandra Kunavarapu, Methodist Hospital, San Antonio, Texas, USA; Lorenzo Peluso, Department of Intensive Care, Erasme Hospital, Université Libre de Bruxelles, Brussels, Belgium; Sebastian Muenz, SLK-Hospital Heilbronn, Germany; Monica Buerle, RKH Hospital Ludwigsburg, Germany; Naveen G. Nagaraj, Heart Center, University Hospital Zurich, Switzerland; Sebastian Nuding, Department of Medicine III, University Clinic Halle (Saale), Germany; Catalin Toma, University of Pittsburgh Medical Center (UPMC), Pennsylvania, USA; Vadim Gudzenko, UCLA Healthcare System, Los Angeles, USA; Hans Joachim Stemmler, Medical Department III, LMU Hospital Munich, Germany; Federico Pappalardo, Department of Anesthesia and Intensive Care, IRCCS ISMETT, UPMC Italy, Palermo, Italy; Georg Trummer, Department of
Cardiovascular Surgery, Heart Center, University of Freiburg, Germany; Christoph Benk, Department of Cardiovascular Surgery, Heart Center, University of Freiburg, Germany; Guido Michels, Department of Acute and Emergency Care, St. Antonius Hospital Eschweiler, Eschweiler, Germany; Christoph Bode, Department of Medicine III (Interdisciplinary Medical Intensive Care), Medical Center, Faculty of Medicine, University of Freiburg, Germany, Department of Cardiology and Angiology I, Heart Center, University of Freiburg, Germany; Daniel Duerschmied, Department of Medicine III (Interdisciplinary Medical Intensive Care), Medical Center, Faculty of Medicine, University of Freiburg, Germany, Department of Cardiology and Angiology I, Heart Center, University of Freiburg, Germany; Constantin von zur Muehlen, Department of Medicine III (Interdisciplinary Medical Intensive Care), Medical Center, Faculty of Medicine, University of Freiburg, Germany, Department of Cardiology and Angiology I, Heart Center, University of Freiburg, Germany; Klaus Kaier, Department of Cardiology and Angiology I, Heart Center, University of Freiburg, Germany, Institute of Medical Biometry and Statistics, Faculty of Medicine, University of Freiburg, Germany, Daniel Brodie, Columbia University College of Physicians \& Surgeons/New York-Presbyterian Hospital, New York, USA, Center for Acute Respiratory Failure, Columbia University Medical Center, New York, USA; Tobias Wengenmayer, Department of Medicine III (Interdisciplinary Medical Intensive Care), Medical Center, Faculty of Medicine, University of Freiburg, Germany, Department of Cardiology and Angiology I, Heart Center, University of Freiburg, Germany.

\section{Authors' contributions}

All authors' contributions to this work comply with ICMJE authorship recommendations. AS and DLS designed the study. Data collection was conducted by AS, JDV, CK, FST, LP, DS, SM, MU, MB, PML, MH, NN, SZ, AV, SN, RR, CT, DBo, VG, SSS, HJS, AM, FP, TS, OM, and DLS. Data was evaluated by AS, KK, TW and DLS. AS, TW, and DLS wrote the first draft of the manuscript. GM, DD, CVzM, GT, $\mathrm{CBe}, \mathrm{CBO}$ and $\mathrm{DBr}$ assisted in data evaluation and reviewed the manuscript. All authors read and approved the final manuscript.

\section{Funding}

Open Access funding enabled and organized by Projekt DEAL. This work was financed by internal funds from the participating institutions.

\section{Availability of data and materials}

All data will be available from the corresponding author on reasonable request.

\section{Ethics approval and consent to participate}

The study was approved by the leading institutional ethics committee of the University of Freiburg (EK 329/20). Due to the retrospective and observational nature of the study and anonymous data evaluation, the need for informed consent was waived.

\section{Consent for publication}

Not applicable. 


\section{Competing interests}

All authors have completed the ICMJE form (available upon request from the corresponding author). FS Taccone reports personal fees from Eurosets outside the submitted work. C Benk and G Trummer are shareholders of Resuscitec $\mathrm{GmbH}$ and received personal fees from Resuscitec $\mathrm{GmbH}$ outside the submitted work. C Benk and G Trummer hold patents US 10695407 and EU 3016675 issued to Resuscitec $\mathrm{GmbH}$. D Brodie reports grants from ALung Technologies, personal fees from Baxter, personal fees from Xenios, personal fees from Abiomed, and unpaid consultancy for Hemovent outside the submitted work. G Michels reports personal fees from ZOLL, Sedana Medical, Orion Pharma, and Getinge outside the submitted work; the competing interests are not related to the present work. All other authors declare no competing interests.

\section{Author details}

${ }^{1}$ Department of Medicine III (Interdisciplinary Medical Intensive Care), Medical Center, Faculty of Medicine, University of Freiburg, Hugstetter Strasse 55, 79106 Freiburg, Germany. ${ }^{2}$ Department of Cardiology and Angiology I, Heart Center, University of Freiburg, Freiburg, Germany. ${ }^{3}$ Heidelberg Institute of Global Health, University of Heidelberg, Heidelberg, Germany. ${ }^{4}$ Department of Intensive Care, Erasme Hospital, Université Libre de Bruxelles, Brussels, Belgium. ${ }^{5}$ Department of Internal Medicine V - Pneumology, Allergology and Critical Care Medicine, Saarland University Medical Center and University of Saarland, Homburg, Germany. ${ }^{6}$ Department of Anesthesiology, Intensive Care Medicine and Pain Management, Hospital Ibbenbueren, Ibbenbueren, Germany.

Received: 3 December 2020 Accepted: 2 February 2021

Published online: 01 March 2021

\section{References}

1. Schmidt M, Hajage D, Lebreton G, Monsel A, Voiriot G, Levy D, Baron E, Beurton A, Chommeloux J, Meng P, et al. Extracorporeal membrane oxygenation for severe acute respiratory distress syndrome associated with COVID-19: a retrospective cohort study. Lancet Respir Med. 2020;8(11):1121-31.

2. Barbaro RP, MacLaren G, Boonstra PS, Iwashyna TJ, Slutsky AS, Fan E, Bartlett $\mathrm{RH}$, Tonna JE, Hyslop R, Fanning JJ, et al. Extracorporeal membrane oxygenation support in COVID-19: an international cohort study of the Extracorporeal Life Support Organization registry. Lancet. 2020:396(10257):1071-8.

3. Rajagopal K, Keller SP, Akkanti B, Bime C, Loyalka P, Cheema FH, Zwischenberger JB, El Banayosy A, Pappalardo F, Slaughter MS, et al. Advanced pulmonary and cardiac support of COVID-19 patients: emerging recommendations from ASAIO-A "Living Working Document." ASAIO J. 2020;66(6):588-98.

4. MacLaren $G$, Combes A, Brodie D. Saying no until the moment is right: initiating ECMO in the EOLIA era. Intensive Care Med. 2020;46(10):1894-6.

5. Combes A, Hajage D, Capellier G, Demoule A, Lavoue S, Guervilly C, Da Silva D, Zafrani L, Tirot P, Veber B, et al. Extracorporeal membrane oxygenation for severe acute respiratory distress syndrome. N Engl J Med. 2018;378(21):1965-75.

\section{Publisher's Note}

Springer Nature remains neutral with regard to jurisdictional claims in published maps and institutional affiliations.
Ready to submit your research? Choose BMC and benefit from:

- fast, convenient online submission

- thorough peer review by experienced researchers in your field

- rapid publication on acceptance

- support for research data, including large and complex data types

- gold Open Access which fosters wider collaboration and increased citations

- maximum visibility for your research: over $100 \mathrm{M}$ website views per year

At BMC, research is always in progress.

Learn more biomedcentral.com/submissions 